Article

\title{
Development and Performance Evaluation of Eco-Friendly POSS-Containing MQL Oil Coolant for Drilling Processes
}

\author{
Ki Beom Park ${ }^{1}$, Dong-Soo Shin ${ }^{2}$ and Young Tae Cho ${ }^{1, *(1)}$ \\ 1 Department of Mechanical Engineering, Changwon National University, 20 Changwondae-ro, Uichang-gu, \\ Changwon-si, Gyeongsangnam-do 51140, Korea; give79me@changwon.ac.kr \\ 2 Department of Chemistry, Changwon National University, 20 Changwondae-ro, Uichang-gu, Changwon-si, \\ Gyeongsangnam-do 51140, Korea; dsshin@changwon.ac.kr \\ * Correspondence: ytcho@changwon.ac.kr; Tel.: +82-55-213-2856
}

Received: 16 March 2020; Accepted: 13 April 2020; Published: 16 April 2020

check for updates

\begin{abstract}
Drilling work on Inconel, a well-known super-heat-resistant alloy, requires a significant quantity of cutting oil to prevent heat-induced abrasion and damage to the cutting tool, caused by the strength and toughness of the alloy. This high requirement of cutting oil, however, negatively affects the processing environment; therefore, minimum-quantity lubrication (MQL), an eco-friendly cutting-oil-supply method, is attracting attention. The conventional MQL method, however, has the disadvantage that an oil-mist is produced along with high-pressure air; hence, the mist is scattered in the air, making the application of the oil to the cutting point inefficient and rendering the cooling effect to be less than that in wet processing. In this study, therefore, an eco-friendly compound, polyhedral oligomeric silsesquioxane (POSS) — a nanostructured organic-inorganic hybrid material that exhibits better adhesion to materials than conventional MQL-specific oil and is resistant to the heat generated during drilling - was developed by adding POSS to the conventional MQL-specific oil, and the effects were verified.
\end{abstract}

Keywords: polyhedral oligomeric silsesquioxane (POSS); eco-friendly cutting oil; MQL; Inconel; drilling

\section{Introduction}

The use of ultra-light, hardened, and difficult-to-cut materials such as Inconel and titanium alloys is rapidly increasing, especially in high-tech flagship industries such as aviation, space, and automobiles. Inconel, a representative super-heat-resistant alloy, has extremely desirable features, such as high strength, tenacity, high-temperature durability, and corrosion resistance [1-3]. These mechanical properties, however, reduce the machinability and thus, cause problems such as economic loss due to the wear and breakage of tools, resulting from the heat generated during drilling work [4-9]. To minimize the heat generation during drilling, a large amount of coolant is supplied. However, this leads to the deterioration of the work environment, environmental pollution, and physical damage to the workers, owing to splashing and leakage of the coolant. To address this, minimum-quantity lubrication (MQL) - a method of supplying an eco-friendly cutting oil that maximizes cooling and lubrication while minimizing the cutting oil quantity-has attracted considerable attention, and several efforts have been made to introduce the practical use of this technology [10-16]. In the MQL method, however, because the oil mist is sprayed with high-pressure air and is thus easily scattered, it is impossible to efficiently supply the cutting oil to the cutting point. In addition, the fact that the oil is easily decomposed by the heat generated during drilling work renders this method less effective than conventional wet processing. 
To overcome these limitations, this study focused on developing an eco-friendly polyhedral oligomeric silsesquioxane (POSS)-containing MQL oil that is more resistant to the heat generated in drilling work, and exhibits a stronger adhesive force toward materials, compared with conventional MQL-specific oil. This was achieved by adding POSS—an organic-inorganic hybrid nanomaterial—to existing MQL-specific oil. For this purpose, the optimal concentration of the POSS ester compound was determined via adhesion experiments in which three kinds of POSS ester compounds were designed and added to the MQL-specific oil at varying concentrations. The resulting cutting oil was used in MQL drilling work on Inconel 601, and the effects were compared with those of normal MQL-specific oil, to evaluate the effectiveness of the POSS-containing MQL oil.

\section{Design of POSS-Containing MQL Oil}

\subsection{POSS}

The polyhedral oligomeric silsesquioxane (POSS) molecules are well-defined organosilicon compounds consisting of rigid silica cores (Si-O-Si) surrounded by functional organic groups, as shown in Figure 1a, and have the structure of a newly added organic substituent $(\mathrm{R})$ on the outside and silicon (Si) and oxygen $(\mathrm{O})$ on the inside. Due to their finely tunable physical and chemical properties, POSSs meet the requirements of both science and industry, the most recognizable and best known of this being cubic T8 with either one or eight functional group derivatives.

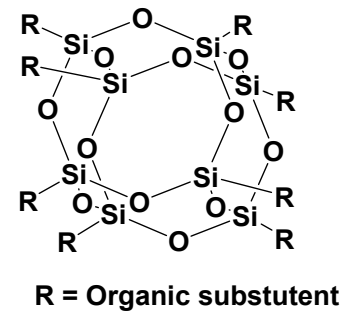

(a)

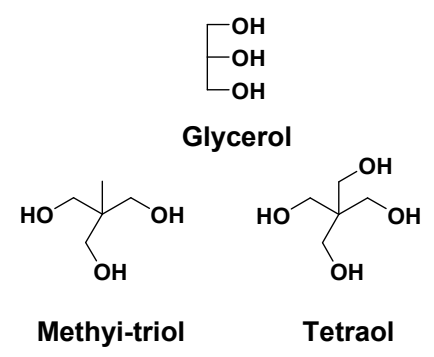

(b)

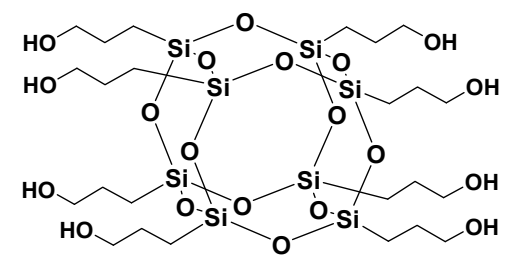

(c)

Figure 1. Structures of (a) POSS, (b) vegetable ester compound, and (c) octa-POSS-OH.

The average diameter of a POSS molecule is approximately $0.5 \mathrm{~nm}$, indicating a dense structure, which results in high chemical and thermal stabilities. This compound can be introduced into various materials, depending on the type of the organic substituent $(R)$ outside the main chain. In addition, it may be used as a side chain of organic polymers or blended as an additive, to develop organic and inorganic hybrid materials with different properties. This means that the POSS is highly applicable when used as a nanocomposite rather than when used alone [17-20]. Further, POSS, an organic and inorganic hybrid nanostructure, can be easily introduced to a functional group through a chemical reaction, allowing their molecular weight to be controlled [21,22].

Conventional MQL-specific oils, as shown in Figure 1b, are made of various vegetable ester compounds such as glycerol, methyl-triol, and tetraol with three or four $\mathrm{OH}$ functional groups. However, octa-POSS-OH compounds, as shown in Figure 1c, have as many as eight functional groups compared with these vegetable ester compounds, meaning that one octa-POSS-OH is capable of producing eight ester compounds and having excellent lubricant properties, thus being an effective candidate for efficient cutting oil. This study, therefore, aimed to develop an eco-friendly POSS-containing MQL oil by designing three kinds of POSS ester compounds with the structural frame of octa-POSS-OH and adding them to conventional MQL-specific oils. 


\subsection{Synthesis of POSS Ester Compound}

Figure 2 shows the process of preparing the octa-chloro-POSS, used as a basic structure for producing the three kinds of POSS ester compounds designed in this study, as described in previous studies [21,23]. After reacting triethoxysilane with $\mathrm{HCl}$ and $\mathrm{H}_{2} \mathrm{O}$ for $48 \mathrm{~h}$, di- $n$-butyltin dilaurate was added to react again for $48 \mathrm{~h}$ at room temperature, producing octa-chloro-POSS with a yield of $35 \%$. These synthesized octa-chloro-POSSs were reacted with potassium octanoate using $5 \mathrm{~mol} \%$ potassium iodide (KI) as a catalyst and $5 \mathrm{~mL}$ of dimethyl formamide (DMF) as a solvent for $8 \mathrm{~h}$ at $10^{\circ} \mathrm{C}$ to produce POSS C8, in which an organic substituent (R) is linked to eight carbon atoms. Figure 3a displays a schematic diagram highlighting the process of preparing POSS-C 8 . Figure $3 \mathrm{~b}$ depicts the process of designing POSS-C2, wherein octa-chloro-POSS is used as the structural frame, as in the case of POSS-C8. The sodium acetate was reacted with the octa-chloro-POSS using $5 \mathrm{~mol} \% \mathrm{KI}$ as a catalyst and $5 \mathrm{~mL}$ of DMF as a solvent for $48 \mathrm{~h}$ at $100{ }^{\circ} \mathrm{C}$, to produce POSS-C2, in which an organic substituent $(\mathrm{R})$ is linked to two carbon atoms.
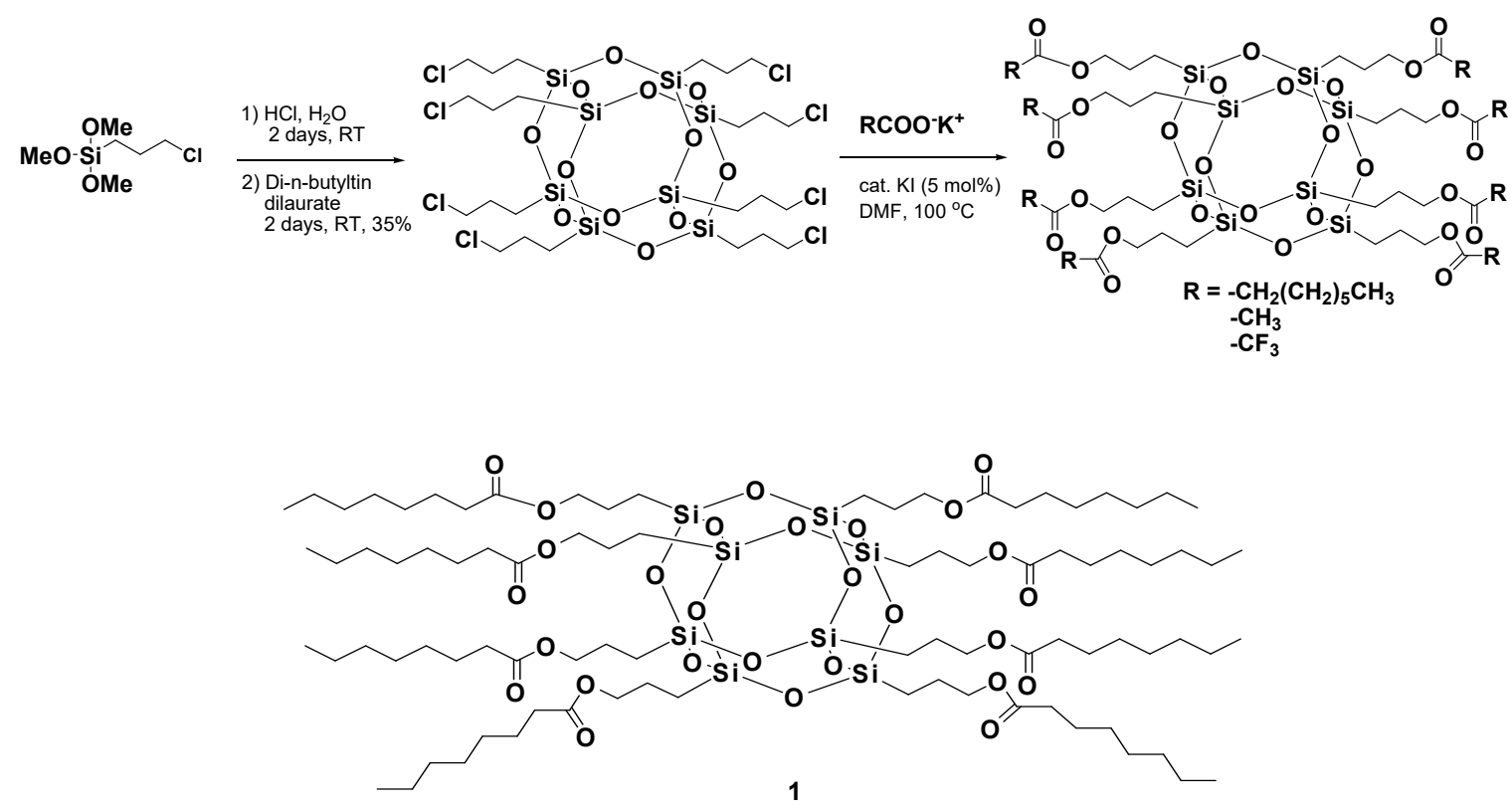

(a)

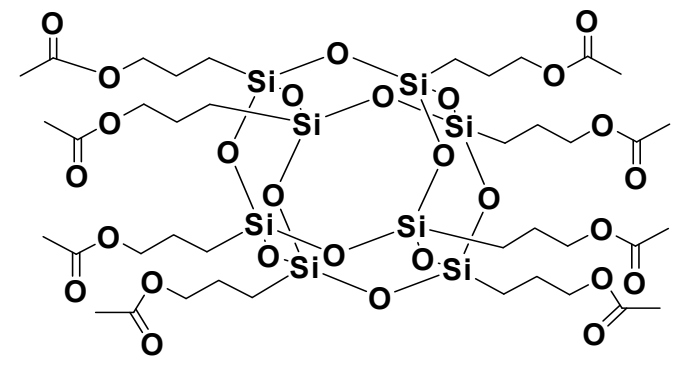

2

(b)

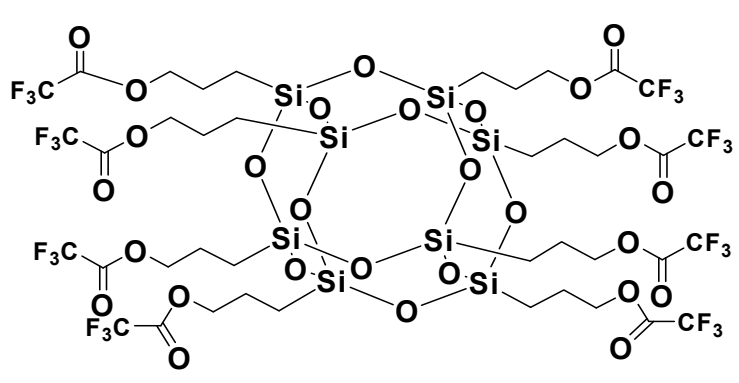

3

(c)

Figure 2. Synthesis of POSS ester compounds [22,23]: (a) POSS-C8 (1). (b) POSS-C2 (2). (c) POSS-C1CF 3 (3). 


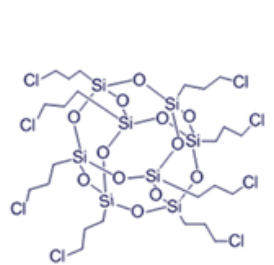

(a)
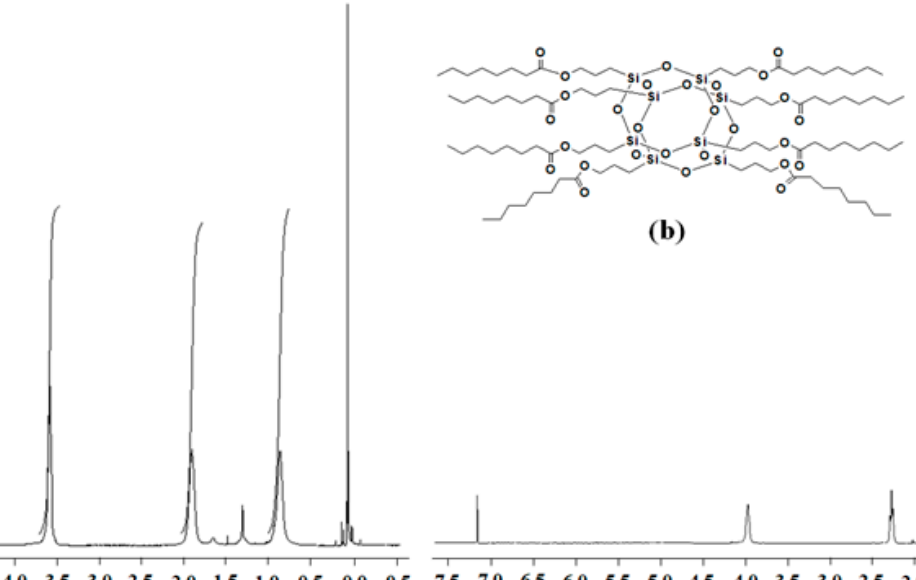

(b)

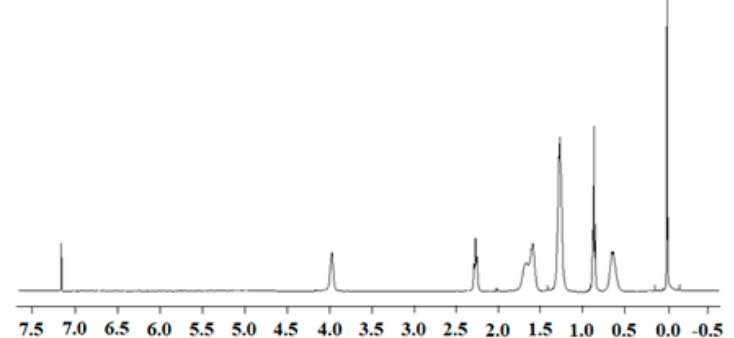

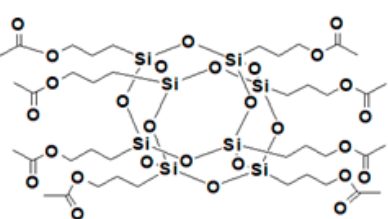

(c)

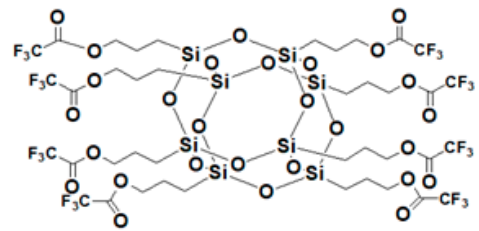

(d)

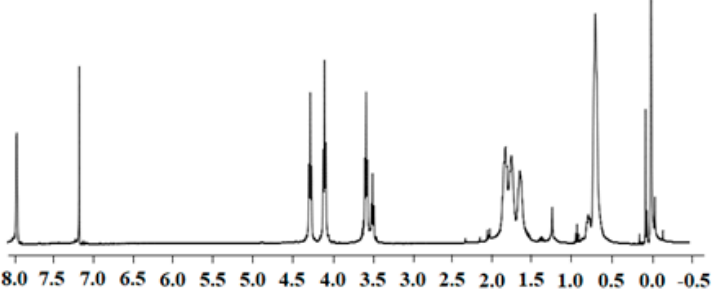

$\begin{array}{lllllllllllllllllllllll}8.0 & 7.5 & 7.0 & 6.5 & 6.0 & 5.5 & 5.0 & 4.5 & 4.0 & 3.5 & 3.0 & 2.5 & 2.0 & 1.5 & 1.0 & 0.5 & 0.0 & -0.5\end{array}$

Figure 3. ${ }^{1} \mathrm{H}-\mathrm{NMR}$ spectrum of POSS-compounds in $\mathrm{CDCl}_{3}$. (a) Octa-chloro-POSS: $\delta 0.78(\mathrm{t}, 16 \mathrm{H}$, $\mathrm{SiCH}_{2}$ ), 1.84 (qui, 16H, $\left.\mathrm{CH}_{2}\right), 3.53\left(\mathrm{t}, 16 \mathrm{H}, \mathrm{CH}_{2} \mathrm{Cl}\right)(\mathbf{b})$ POSS-C8 (1): $\delta 4.09-3.97(\mathrm{~m}, 16 \mathrm{H}), 2.30-2(\mathrm{t}$, $\mathrm{J}=7.32 \mathrm{~Hz}, 16 \mathrm{H}), 1.67-1.56(\mathrm{~m}, 32 \mathrm{H}), 1.37-1.19(\mathrm{~m}, 64 \mathrm{H}), 0.88(\mathrm{t}, \mathrm{J}=7.32 \mathrm{~Hz}, 24 \mathrm{H}), 0.72-0.59(\mathrm{~m}, 16 \mathrm{H})$

(c) POSS-C2 (2): $\delta 4.05-4.02(\mathrm{t}, \mathrm{J}=6.4 \mathrm{~Hz}, 16 \mathrm{H}), \delta 2.06(\mathrm{~s}, 24 \mathrm{H}), \delta 1.71-1.70(\mathrm{~m}, 16 \mathrm{H}), \delta 0.68-0.64(\mathrm{t}, \mathrm{J}=8.4$

$\mathrm{Hz}, 16 \mathrm{H})(\mathrm{d}) \mathrm{POSS}_{-\mathrm{C} 1 \mathrm{CF}_{3}}(3): \delta 4.35-4.13(\mathrm{~m}, 16 \mathrm{H}), \delta 1.85-1.81(\mathrm{~m}, 16 \mathrm{H}), \delta 0.73-0.69(\mathrm{t}, \mathrm{J}=8.4 \mathrm{~Hz}, 16 \mathrm{H})$.

POSS- $\mathrm{C}_{1} \mathrm{CF}_{3}$ was designed by adding potassium trifluoroacetate, a popular additive for conventional cutting oil, to strengthen the heat resistance. The identification of each compound by ${ }^{1} \mathrm{H}-\mathrm{NMR}$ is shown in Figure 3, and TGA analysis has already been performed for POSS ester [23].

\section{Apparatus and Methods}

The machine tool used for the Inconel 601 drilling experiment in this study was a SIRIUS-2 3-axis machining center (Hwachen, Korea), and the drill used was a tungsten carbide drill (DH 423050, YG1) coated with TiAlN. The wear of the drill tip was measured using a tool microscope (SOMETECH, Korea). The oil-mist supply device (MQL device) was a Vario UFV 10-003 (Vogel, Germany), and Lubri Fluid F100 was used as the MQL-specific oil. In the adhesion experiment of the POSS-containing MQL oil, the POSS ester compounds with varying concentrations $(\mathrm{P})$ and flow rates $(\mathrm{Q})$ were added into the MQL-specific oil; the mixtures were used to perform drilling for $5 \mathrm{~min}$ using the MQL device; the weight of the oils in relation to the drill were measured. The drilling-evaluation experiment was performed using a $5 \Phi$ drill coated with TiAlN, with the following conditions: spindle speed $\left(\mathrm{V}_{\mathrm{s}}\right)=500 \mathrm{rpm}$, feed $(\mathrm{f})=0.05 \mathrm{~mm} / \mathrm{rev}$, oil-mist flow rate $(\mathrm{Q})=60,120,180$, and $240 \mathrm{~mL} / \mathrm{h}$, and step feed $(\mathrm{mm} \times$ times $)=2 \times 3$, applying a sealed cover. 


\section{Effects of POSS-Containing MQL Oil}

\subsection{Adhesion Evaluation of POSS-Containing MQL Oil}

The POSS-containing MQL oils were prepared by mixing the POSS-C8 (1)(0.1\%), POSS-C2 (2) $(0.4 \%)$, and POSS-C $1 \mathrm{CF}_{3}(3)(0.8 \%)$, synthesized in this study, with MQL-specific oil (1.6\%). For the evaluation of adhesion, the modified oil was sprayed for $5 \mathrm{~min}$ onto the drill, at flow rates of $60 \mathrm{~mL} / \mathrm{h}$, $120 \mathrm{~mL} / \mathrm{h}, 180 \mathrm{~mL} / \mathrm{h}$, and $240 \mathrm{~mL} / \mathrm{h}$. The weight of the oils in adherence with the drill were then measured, as shown in Figure 4 [24]. (However, since the amount of adhered oil is minimal, it does not flow down.) The $\mathrm{x}$ - and y-axes in Figures 5-7 indicate that the concentrations of POSS-C8, POSS$\mathrm{C} 2$, and POSS-C1CF 3 and the weight of the POSS-containing MQL oils effectively adhered to the drill, respectively. The concentration value of zero for the POSS-C8, POSS-C2, and POSS-C1CF 3 represents the conventional MQL-specific oil (to which the POSS is not added). As represented in the graphs, the amount of adhered oil increased with growing concentrations of POSS-C8, POSS-C2, and POSS-C1CF 3 , and increased up to $60 \%$ compared with that of the conventional MQL-specific oil. A possible explanation for this result is that the molecular weight of POSS-containing MQL oil increased in conjunction with the POSS concentration while the amount of oil scattered in the air is reduced. Furthermore, additional bindings may occur between POSS from the oil and the metal surface, leading to the increase in adhesion.

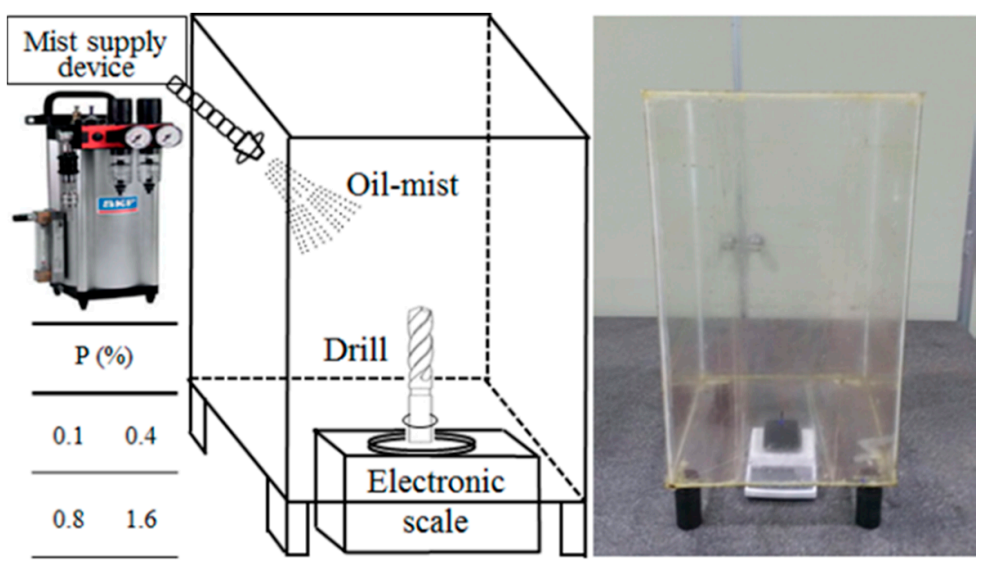

Figure 4. Experimental setup for adhesion test.

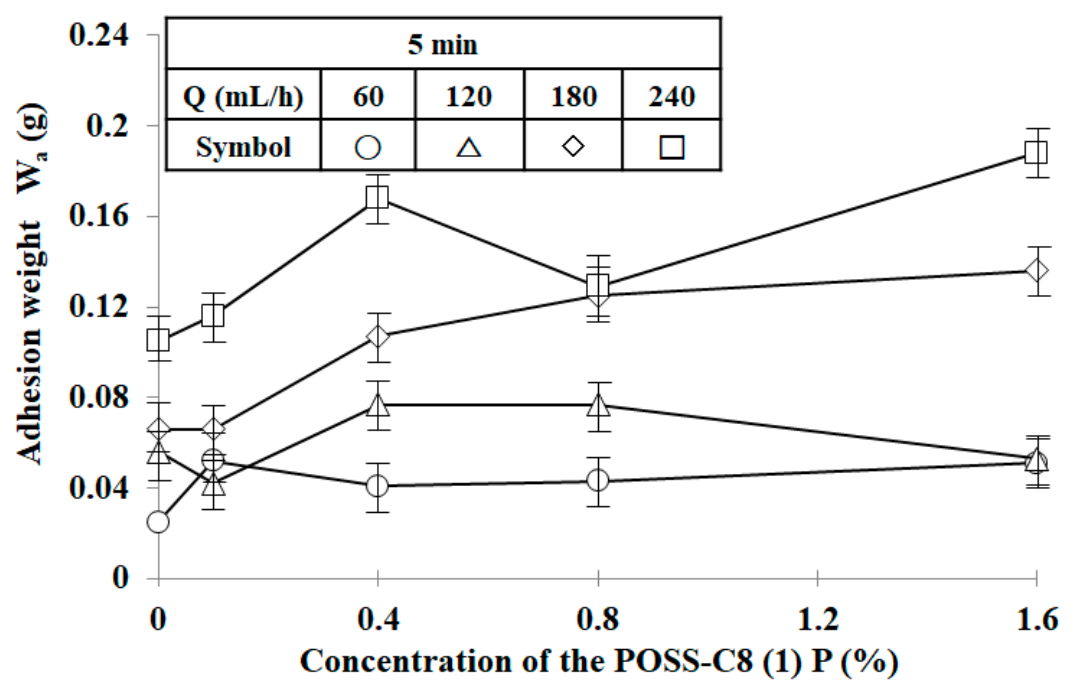

Figure 5. Relationship between $\mathrm{W}_{\mathrm{a}}$ and POSS-C8 (1) concentration. 


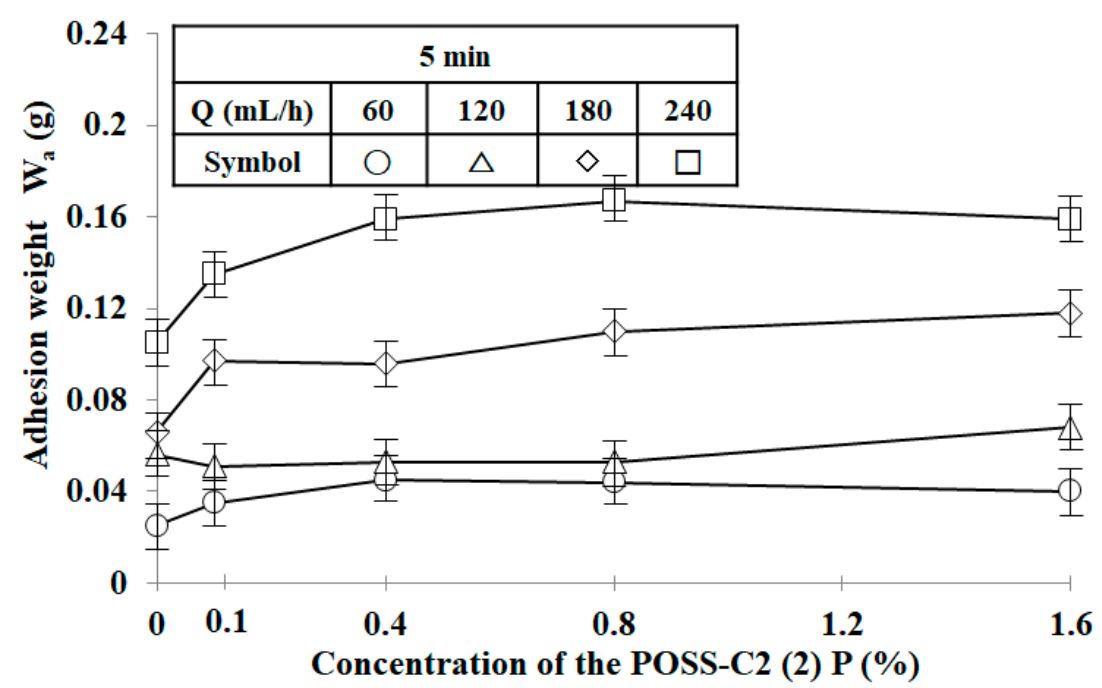

Figure 6. Relationship between $\mathrm{W}_{\mathrm{a}}$ and POSS-C2 (2) concentration.

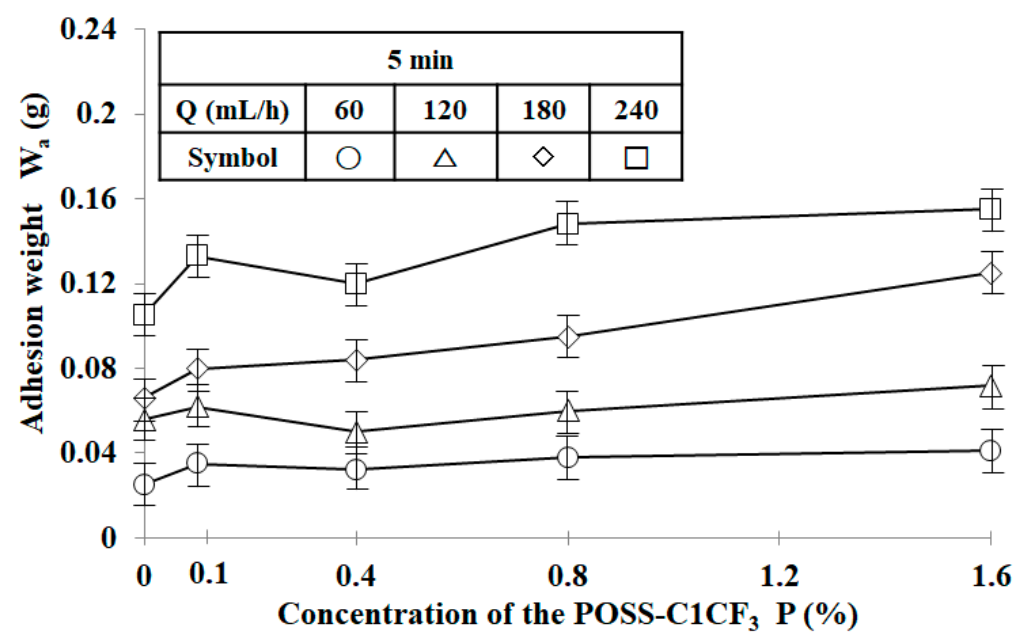

Figure 7. Relationship between $\mathrm{W}_{\mathrm{a}}$ and POSS $\mathrm{ClCF}_{3}$ (3) concentration.

\subsection{Drilling Evaluation of POSS-Containing MQL Oil}

Drilling evaluation was performed for the POSS-C8, POSS-C2, and POSS-C1CF 3 synthesized in this study, for all the concentration values. The drilling evaluation employed a sealed cover, and the conditions and MQL flow rate were those proposed by Park [24], to ensure the effective drilling of Inconel 601; the parameters were as follows: $\mathrm{V}_{\mathrm{s}}=500 \mathrm{rpm}, \mathrm{f}=0.05 \mathrm{~mm} / \mathrm{rev}, \mathrm{Q}=240 \mathrm{~mL} / \mathrm{h}$, and step feed $=2 \times 3$. Figure 8 shows the change in the life span $\left(\mathrm{L}_{\mathrm{f}}\right)$ of the tool. The $\mathrm{x}$ - and $\mathrm{y}$-axes in Figure 8 indicate the concentrations (P) of POSS-C 8 , POSS- $\mathrm{C} 2$, and POSS- $\mathrm{C}^{-\mathrm{CF}_{3}}$ and the drilled length until the tool fracture $\left(\mathrm{L}_{\mathrm{f}}\right)$, respectively. The $\mathrm{L}_{\mathrm{f}}$ values were expressed as the averages of the data from the three replicates. In the case of POSS-C $8, \mathrm{~L}_{\mathrm{f}}$ was found to decrease with an increasing concentration. It was inferred that this occurred because the longer carbon chain containing eight carbon atoms linked with the organic substituent solidified the MQL-specific oil, weakening the lubrication during the drilling work. In contrast, in the case of POSS-C2, in which the organic substituent was linked to two carbon atoms, the performance was superior for the concentration of $0.8 \%$ (the $\mathrm{L}_{\mathrm{f}}$ is about $8000 \mathrm{~mm}$ ) and decreased for concentrations of $1.2 \%$ and above. Figure 9 shows tool wear according to concentrations $\mathrm{P}(\%)$. The drilling length of the POSS $0 \%$ (non-modified MQL oil) was fractured at $2472 \mathrm{~mm}$ and the POSS-C2 $0.8 \%$ showed a considerably reduced tool wear when the drilling length was $2472 \mathrm{~mm}$ fracturing at $8000 \mathrm{~mm}$. It is considered that concentrations over 1\%, owing to the nature 
of POSS, cause changes in the original characteristics of oil and degrades the lubricant performance of the MQL-specific oil. The POSS- $\mathrm{C}_{1} \mathrm{CF}_{3}$, which was synthesized by applying $-\mathrm{CF}_{3}$ to improve the heat resistance of MQL-specific oil, as with POSS-C8, was shown to negatively affect $\mathrm{L}_{\mathrm{f}}$. It was inferred that, considering POSS is generally the connected $\mathrm{CF}_{3}$ group as opposed to $\mathrm{CH}_{3}$, it had a negative effect on the lubrication performance.

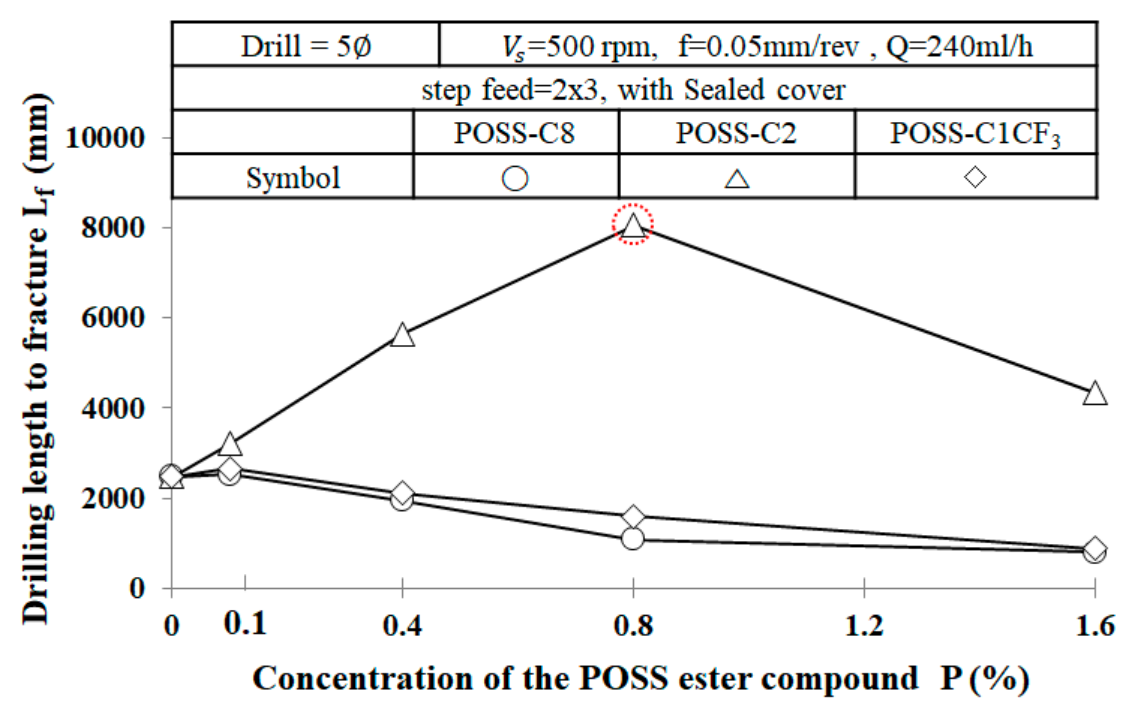

Figure 8. Relationship between $\mathrm{L}_{\mathrm{f}}$ and POSS concentration in the cutting oil.

\begin{tabular}{|c|c|c|c|c|c|}
\hline \multicolumn{6}{|c|}{ Drill $=5 \emptyset, \mathrm{V}_{\mathrm{s}}=500 \mathrm{rpm}, \mathrm{f}=0.05 \mathrm{~mm} / \mathrm{rev}$, step feed $=2 \times 3, \mathrm{Q}=240 \mathrm{~mL} / \mathrm{h}$} \\
\hline $\mathrm{P}(\%)$ & 0 & 0.1 & 0.4 & 0.8 & 1.6 \\
\hline Drilling Length (mm) & \multicolumn{5}{|c|}{888} \\
\hline POSS-C 8 & & & & & fractur \\
\hline Drilling Length (mm) & \multicolumn{5}{|c|}{2472} \\
\hline POSS-C2 & actu & & & & \\
\hline Drilling Length (mm) & \multicolumn{5}{|c|}{804} \\
\hline POSS-C1CF 3 & & & & & \\
\hline
\end{tabular}

Figure 9. Comparison of tool wear according to $\mathrm{P}(\%)$.

\section{Conclusions}

This study focused on developing POSS-containing MQL oils with excellent adhesion to material and great resistance to the heat generated during drilling. This was achieved by adding POSS to conventional MQL-specific oil. For this purpose, POSS-C8, POSS-C2, and POSS- $\mathrm{C}_{1} \mathrm{CF}_{3}$ were designed, and adhesion evaluations were performed by adding them to the MQL-specific oil at various concentrations. The results showed that higher concentrations of POSS-C8, POSS-C2, and POSS- $\mathrm{C}_{1} \mathrm{CF}_{3}$ led to a better adhesion with the cutting tool, with the adhered amounts of oil having increased up to $60 \%$ compared with conventional oil. In addition, the results of the drilling evaluation in relation 
to the concentrations of POSS-C8, POSS-C2, and POSS-F showed that, in POSS-C 8 and POSS-C1CF 3 , higher concentrations reduced $\mathrm{L}_{\mathrm{f}}$ owing to the degraded lubricant performance compared with the conventional MQL-specific oil. The results for the POSS-C2, on the contrary, showed that the lower concentration of $0.8 \%$ improved $\mathrm{L}_{\mathrm{f}}$ fourfold compared to the conventional MQL-specific oil; however, concentrations of over $0.8 \%$ reduced $\mathrm{L}_{\mathrm{f}}$. It is expected, therefore, that the use of the POSS-containing MQL oil (POSS-C2 0.8\%) developed in this study can help to overcome the shortcomings of the conventional MQL method, achieving lubrication performance comparable to that of wet processing and ensuring eco-friendly working conditions.

Author Contributions: K.B.P. investigation, visualization, validation, data curation, writing-original draft; D.-S.S.: resources, methodology, formal analysis, writing-original draft; Y.T.C.: conceptualization, writing-review and editing, supervision, project administration, funding acquisition. All authors have read and agreed to the published version of the manuscript.

Funding: This work was supported by the National Research Foundation of Korea (NRF) grant funded by the Korea government (MSIT) (No. 2019R1A5A808320111) and 2016R1D1A1B01011019).

Acknowledgments: The authors appreciate Kyung-Min Choi for getting the ${ }^{1} \mathrm{H}-\mathrm{NMR}$ data and this work was also supported by the Smart Manufacturing Technology Center \& MAKER AGIT in Changwon National University.

Conflicts of Interest: The authors declare no conflict of interest.

\section{Nomenclature}

$\mathrm{V}_{\mathrm{S}} \quad$ Spindle speed (rpm)

F Feed rate $(\mathrm{mm} / \mathrm{rev})$

$\mathrm{F}_{\mathrm{t}} \quad$ Thrust force $(\mathrm{N})$

$\mathrm{F}_{\mathrm{f}} \quad$ Fluctuation width of thrust force $(\mathrm{N})$

L Drilling length (mm)

$\mathrm{L}_{\mathrm{f}} \quad$ Drilling length to fracture $(\mathrm{mm})$

$\mathrm{P} \quad$ Consistence of POSS ester compound (\%)

$P_{\mathrm{o}} \quad$ Oil mist pressure (bar)

$\mathrm{P}_{\mathrm{a}} \quad$ Air pressure (bar)

Q Oil mist flow rate $(\mathrm{ml} / \mathrm{h})$

$\mathrm{W}_{\mathrm{a}} \quad$ Average weight $(\mathrm{g})$

\section{References}

1. Choudhury, I.A.; El-Baradie, M.A. Machinability of nickel-base super alloys: A general review. J. Mater. Process. Tech. 1998, 77, 278-284. [CrossRef]

2. Rahman, M.; Seah, W.K.H.; Teo, T.T. The machinability of Inconel 718. J. Mater. Process. Tech. 1997, 63, 199-204. [CrossRef]

3. Nalbant, M.; Altın, A.; Gökkaya, H. The effect of coating material and geometry of cutting tool and cutting speed on machinability properties of Inconel 718 super alloys. Mater. Des. 2007, 28, 1719-1724. [CrossRef]

4. Maiyar, L.M.; Ramanujam, R.; Venkatesan, K.; Jerald, J. Optimization of machining parameters for end milling of Inconel 718 super alloy using Taguchi based grey relational analysis. Procedia Eng. 2013, 64, 1276-1282. [CrossRef]

5. Tian, X.; Zhao, J.; Zhao, J.; Gong, Z.; Dong, Y. Effect of cutting speed on cutting forces and wear mechanisms in high-speed face milling of Inconel 718 with Sialon ceramic tools. Int. J. Adv. Manuf. Technol. 2013, 69, 2669-2678. [CrossRef]

6. Zhang, S.; Li, J.; Zhu, X.; Lv, H. Saw-tooth chip formation and its effect on cutting force fluctuation in turning of Inconel 718. Int. J. Precis. Eng. Man. 2013, 14, 957-963. [CrossRef]

7. Woon, K.S.; Chaudhari, A.; Rahman, M.; Wan, S.; Kumar, A.S. The effects of tool edge radius on drill deflection and hole misalignment in deep hole gundrilling of Inconel-718. CIRP Ann. 2014, 63, 125-128. [CrossRef]

8. Baghlani, V.; Mehbudi, P.; Akbari, J.; Sohrabi, M. Ultrasonic assisted deep drilling of Inconel 738LC superalloy. Procedia Cirp. 2013, 6, 571-576. [CrossRef] 
9. Ulutan, D.; Ozel, T. Machining induced surface integrity in titanium and nickel alloys: A review. Int. J. Mach. Tools Manuf. 2011, 51, 250-280. [CrossRef]

10. Biermann, D.; Iovkov, I.; Blum, H.; Rademacher, A.; Taebi, K.; Suttmeier, F.T.; Klein, N. Thermal aspects in deep hole drilling of aluminium cast alloy using twist drills and MQL. Procedia CIRP 2012, 3, 245-250. [CrossRef]

11. Kaynak, Y. Evaluation of machining performance in cryogenic machining of Inconel 718 and comparison with dry and MQL machining. Int. J. Adv. Manuf. Technol. 2014, 72, 919-933. [CrossRef]

12. Tai, B.L.; Stephenson, D.A.; Furness, R.J.; Shih, A.J. Minimum quantity lubrication (MQL) in automotive powertrain machining. Procedia Cirp. 2014, 14, 523-528. [CrossRef]

13. Ji, X.; Li, B.; Zhang, X.; Liang, S.Y. The effects of minimum quantity lubrication (MQL) on machining force, temperature, and residual stress. Int. J. Precis. Eng. Manu. 2014, 15, 2443-2451. [CrossRef]

14. Wang, C.D.; Chen, M.; An, Q.L.; Wang, M.; Zhu, Y.H. Tool wear performance in face milling Inconel 182 using minimum quantity lubrication with different nozzle positions. Int. J. Precis. Eng. Manu. 2014, 15, 557-565. [CrossRef]

15. Park, K.-H.; Yang, G.-D.; Lee, D.Y. Tool wear analysis on coated and uncoated carbide tools in Inconel machining. Int. J. Precis. Eng. Manu. 2015, 16, 1639-1645. [CrossRef]

16. Sanchez, J.A.; Pombo, I.; Alberdi, R.; Izquierdo, B.; Ortega, N.; Plaza, S.; Martinez-Toledano, J. Machining evaluation of a hybrid MQL-CO 2 grinding technology. J. Clean. Prod. 2010, 18, 1840-1849. [CrossRef]

17. Sanchez, C.; Belleville, P.; Popall, M.; Nicole, L. Applications of advanced hybrid organic-inorganic nanomaterials: From laboratory to market. Chem. Soc. Rev. 2011, 40, 696-753. [CrossRef]

18. Sanchez, C.; Boissiere, C.; Grosso, D.; Laberty, C.; Nicole, L. Design, synthesis, and properties of inorganic and hybrid thin films having periodically organized nanoporosity. Chem. Mater. 2008, 20, 682-737. [CrossRef]

19. Zhang, X.; Ma, Z.; Fan, H.; Bittencourt, C.; Wan, J.; Dubois, P. A novel polyhedral oligomeric silsesquioxanemodified layered double hydroxide: Preparation, characterization and properties. Beilstein J. Nanotechnol. 2018, 9, 3053-3068. [CrossRef]

20. Dudziec, B.; Żak, P.; Marciniec, B. Synthetic Routes to Silsesquioxane-Based Systems as Photoactive Materials and Their Precursors. Polymers 2019, 11, 504. [CrossRef]

21. Marciniec, B.; Dutkiewicz, M.; Maciejewski, H.; Kubicki, M. New, effective method of synthesis and structural characterization of octakis (3-chloropropyl) octasilsesquioxane. Organometallics 2008, 27, 793-794. [CrossRef]

22. Kumar, B.P.; Vijaykumar, B.V.D.; Raghavan, C.M.; Harshavardhan, S.J.; Yi, S.S.; Gandhi, S.; Shin, D.S. POSS-based luminescent hybrid material for enhanced photo-emitting properties. J. Mater. Sci. 2013, 48, 7533-7539. [CrossRef]

23. Choi, K.M.; Harshavardhan, S.J.; Sridhar, C.; Vijaykumar, B.V.D.; Kumar, D.; Jang, K.; Shin, D.S. Synthesis of POSS Derived Organic-Inorganic Hybrid Esters for Insulating Oil Applications. Bull. Korean Chem. Soc. 2014, 35, 2769-2773. [CrossRef]

24. Park, K.B.; Cho, Y.T.; Jung, Y.G. Efficient MQL-based Drilling of Inconel 601. J. KSMPE 2018, 17, 1-8. [CrossRef]

(C) 2020 by the authors. Licensee MDPI, Basel, Switzerland. This article is an open access article distributed under the terms and conditions of the Creative Commons Attribution (CC BY) license (http://creativecommons.org/licenses/by/4.0/). 